\title{
Synthesis, enantioseparation and photophysical properties of planar-chiral pillar[5]arene derivatives bearing fluorophore fragments
}

\author{
Guojuan Li, Chunying Fan, Guo Cheng, Wanhua Wu* and Cheng Yang*
}

\author{
Full Research Paper \\ Address: \\ Key Laboratory of Green Chemistry \& Technology, College of \\ Chemistry and Healthy Food Evaluation Research Center, Sichuan \\ University, 29 Wangjiang Road, Chengdu, 610064, P. R. China \\ Email: \\ Wanhua Wu* - wuwanhua@scu.edu.cn; Cheng Yang* - \\ yangchengyc@scu.edu.cn \\ * Corresponding author $\ddagger$ Equal contributors \\ Keywords: \\ aggregation; circular dichroism; chirality; click chemistry; macrocycles; \\ pillar[5]arenes
}

Open Access

Beilstein J. Org. Chem. 2019, 15, 1601-1611.

doi:10.3762/bjoc. 15.164

Received: 30 April 2019

Accepted: 23 May 2019

Published: 18 July 2019

This article is part of the thematic issue "Novel macrocycles - and old ones doing new tricks".

Guest Editor: W. Jiang

(C) 2019 Li et al.; licensee Beilstein-Institut. License and terms: see end of document.

\begin{abstract}
Planar chiral pillar[5]arene derivatives (P5A-DPA and P5A-Py) bearing bulky fluorophores were obtained in high yield by click reaction. The photophysical properties of both compounds were investigated in detail. P5A-DPA with two 9,10-diphenylanthracene (DPA) pigments grafted on the pillar[5]arene showed a high fluorescence quantum yield of $89.5 \%$. This is comparable to the monomer DPA-6, while P5A-Py with two perylene (Py) pigments grafted on the pillar[5]arene showed a significantly reduced quantum yield of $46.4 \%$ vs $78.2 \%$ for the monomer Py-6. The oxygen-through-annulus rotation of the phenolic units was inhibited for both compounds due to the bulky chromophore introduced, and the resolution of the enantiomers was achieved due to the bulky size of the fluorophores. The absolute configuration of the enantiomers was determined by circular dichroism (CD) spectra. The solvent-induced aggregation behavior was investigated with the enantiopure P5A-DPA and P5A-Py. It was found that the CD signals were enhanced by aggregation. P5A-DPA showed aggregation-induced emission enhancement, while P5A-Py showed aggregation-induced emission quenching, accompanied by excimer emission when aggregating in water and THF mixed solution.
\end{abstract}

\section{Introduction}

Planar-chiral compounds are structurally appealing and potentially applicable in various functional materials such as chiral discriminators [1,2], chiral polymers, supramolecular sensors [3] and chiral guest receptors [4,5]. Planar-chiral macrocyclic molecules are particularly interesting in the context of the host-guest complexation properties [6-8]. Pillararenes are typical examples of this type of compounds and have attracted considerable attention due to their facile chemical synthesis and versatile functionality [9] in recent years. Pillar[5] arenes [10], are cyclic pentamers composed of 1,4-dialkoxybenzene units connected through methylene bridges at the para-position and have a unique symmetrical architecture with an overall cylin- 
drical or pillar-like shape. By virtue of their rigid and symmetrical structures, as well as highly tunable functionality, the studies on pillar[5] arenes have been developed rapidly in various areas, such as artificial transmembrane channels $[11,12]$, molecular complexation $[13,14]$ and nonporous adaptive crystals [15-17]. One of the features of pillar[5]arenes that differs from the common macrocycles is the planar chirality resulting from the different orientations of the alkoxy substituents on the rims. Theoretically, eight conformers can be formed including diastereomeric ones: $\left(S_{p}, S_{p}, S_{p}, S_{p}, S_{p}\right),\left(R_{p}, S_{p}, S_{p}, S_{p}, S_{p}\right)$, $\left(R_{p}, R_{p}, S_{p}, S_{p}, S_{p}\right),\left(R_{p}, S_{p}, R_{p}, S_{p}, S_{p}\right)$ and their antipodal enantiomers: $\left(R_{p}, R_{p}, R_{p}, R_{p}, R_{p}\right),\left(S_{p}, R_{p}, R_{p}, R_{p}, R_{p}\right),\left(S_{p}, S_{p}, R_{p}, R_{p}, R_{p}\right)$ $\left(S_{p}, R_{p}, S_{p}, R_{p}, R_{p}\right)$. Among them, the enantiomeric per- $S_{p}$ $\left(S_{p}, S_{p}, S_{p}, S_{p}, S_{p}\right)$ and per- $R_{p}\left(R_{p}, R_{p}, R_{p}, R_{p}, R_{p}\right)$ conformers (abbreviated as $S_{p}$ and $R_{p}$, respectively), in which all of the alkoxy substituents at both rims are oriented in the same direction, are the most stable conformers due to the steric-hindrance effect of the substituents in other conformers. In general, the $S_{p}$ and $R_{p}$ conformers can interconvert from each other in solution through the oxygen-through-annulus rotation along the methylene bridges [18], and the separation of these conformational isomers is impossible.

Inhibiting the rotation of the phenolic units is prerequisite to isolate the isomers. A complexation with a suitable guest molecule, such as a viologen derivative, can significantly slow down the rotation of the phenolic rings, and a conformational interconversion can only occur when the guest molecule decomplexed from the cavity [19-21]. Several strategies have been established to block the interconversion of the $S_{p}$ and $R_{p}$ conformers: Implanting a guest moiety in the pillar[5]arene cavity by rotaxanation or introducing a fused side ring into one of the phenolic rings $[22,23]$. Covalently connected bulky substituents installed on both rims of the pillar[n]arene provided a more straightforward method to inhibit the rotation [24-26]. In per-cyclohexylmethyl-substituted pillar[5]arene the rotation of the phenolic units is blocked and enabled the chiral separation of the $S_{p}$ and $R_{p}$ enantiomers [25]. Also installing bulky substituents onto only one phenolic ring was found to be effective to inhibit the rotation of the units [27-29].

Pillar[5]arene itself shows only moderate absorption and weak fluorescence in the UV region, and the chemical introduction of chromophores onto the rims of pillar[5]arene has been applied to allow its use as receptors for molecular sensing or biological applications [30-33]. It occurred to us that connecting fluorophores with strong absorptions in the visible range and with a high fluorescence quantum yield are beneficial for the application of pillar[5]arene in these fields. Perylene (Py) and 9,10diphenylanthracene (DPA) are well known for their desirable absorption and high fluorescence quantum yield. These chro- mophores possess unique photophysical properties and have been widely used as triplet acceptor for TTA-based upconversion [34-36] and as energy donors in artificial light-harvesting systems [37]. Thus, two pillar[5] arene derivatives P5A-DPA and P5A-Py (Scheme 1), in which two Py and DPA units were chemically grafted onto one of the phenolic units of pillar[5]arene, were designed and synthesized by click reaction $[38,39]$. We supposed that the Py or DPA substituents on both rims of the pillar[5] arenes will serve two purposes: Firstly, the molecular sizes of Py and DPA are larger than the cavity size of the pillar[5]arenes (ca. $5.5 \AA$ ), and the rotation of the units should be inhibited generating a pair of $S_{p}$ and $R_{p}$ enantiomers. Secondly, the strong absorption in the visible range and high fluorescence a quantum yield of the fluorophores will donate the pillar[5]arene derivatives novel photophysical properties.

\section{Results and Discussion Syntheses of pillar[5]arene derivatives}

P5A-Py was synthesized by following our previously reported processes [34], and P5A-DPA was synthesized by the processes illustrated in Scheme 1. The ethynyl-bearing pillar[5] arene derivative P5A was obtained through the co-cyclization of 4.0 equiv of 1,4-dimethoxybenzene with 1.0 equiv of the hydroquinone derivative 7 and 5.0 equiv of paraformaldehyde in the presence of $\mathrm{BF}_{3} \cdot \mathrm{OEt}_{2}$ [40,41]. The product was purified by silica gel column chromatography with hexane/ethyl acetate 10:1 as the eluent. The first fraction was permethylated pillar[5] arene, and P5A was collected as the second fraction in $45 \%$ yield. The subsequent reaction of compound P5A with the azide-substituted DPA derivative DPA-6 was carried out in the presence of $\mathrm{CuSO}_{4} \cdot 5 \mathrm{H}_{2} \mathrm{O}$ (2.0 equiv) and sodium ascorbate (4.0 equiv) for $24 \mathrm{~h}$ in DMF at $65^{\circ} \mathrm{C}$ giving P5A-DPA in almost quantitative conversion (Scheme 1). The crude product was separated from $\mathrm{CuSO}_{4}$ and sodium ascorbate through extraction with $\mathrm{Et}_{2} \mathrm{O} /$ water. Further purification of the crude product was carried out by silica gel column chromatography (dichloromethane/methanol 30:1) to afford P5A-DPA in 72\% yield. The structure of P5A-DPA was characterized by ${ }^{1} \mathrm{H}$ NMR, ${ }^{13} \mathrm{C}$ NMR and high-resolution mass spectrometry (HRMS, Supporting Information File 1, Figures S19-S21).

\section{Photophysical properties}

The photophysical properties were investigted by UV-vis absorption and fluorescence spectroscopy, as well as through fluorescence decay measurements. As shown in Figure 1a, the UV-vis spectrum of P5A-DPA showed two main absorption bands at $270-320 \mathrm{~nm}$ and $350-420 \mathrm{~nm}$, respectively, which were assigned to the absorption bands of the pillar[5]arene moiety and the $\pi \rightarrow \pi^{*}$ transition of the DPA fragment, respectively. The absorption spectra of P5A-DPA and P5A-Py are 

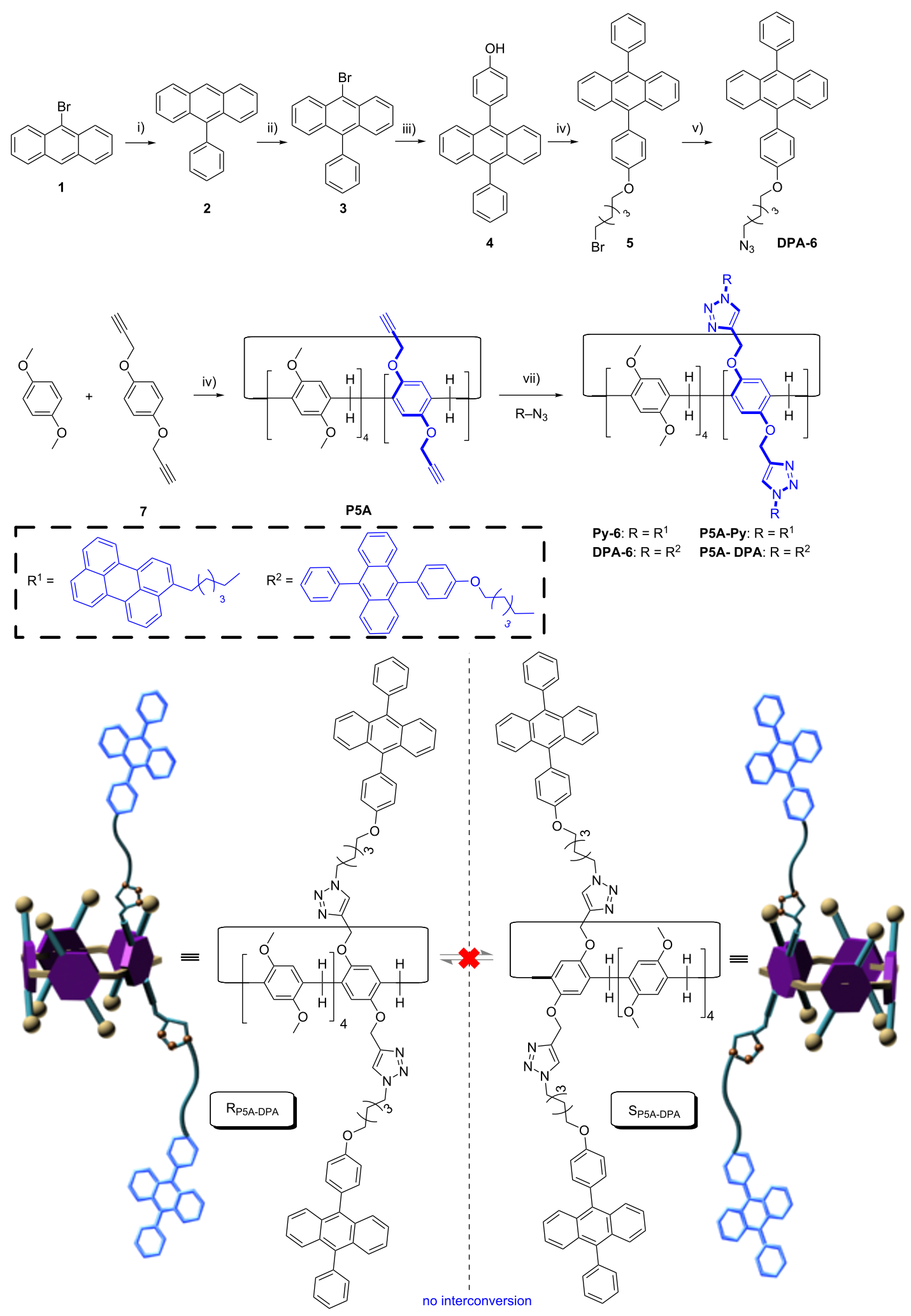

Scheme 1: Preparation of A1/A2-difunctionalized pillar[5]arenes (P5A-DPA and P5A-Py) by click reactions. Reagents and conditions: i) phenylboronic acid, $\mathrm{Pd}\left(\mathrm{PPh}_{3}\right)_{4}, \mathrm{~K}_{2} \mathrm{CO}_{3}, \mathrm{CsF}$, toluene/THF/ $\mathrm{H}_{2} \mathrm{O}, 120^{\circ} \mathrm{C}$, yield: $82 \%$; ii) $\mathrm{N}$-bromosuccinimide, chloroform, $60{ }^{\circ} \mathrm{C}$, yield: $87 \%$; iii) $(4$-hydroxyphenyl)boronic acid, $\mathrm{Pd}\left(\mathrm{PPh}_{3}\right)_{4}, \mathrm{~K}_{2} \mathrm{CO}_{3}, \mathrm{CsF}$, toluene/THF/ $\mathrm{H}_{2} \mathrm{O}$, reflux, $8 \mathrm{~h}$, yield: $70 \%$; iv) $\mathrm{K}_{2} \mathrm{CO}_{3}, 1,5$-dibromopentane, acetone, $80{ }^{\circ} \mathrm{C}$, yield: $67 \%$; v) $\mathrm{NaN}_{3}$, DMF, yield: $84 \%$; vi) paraformaldehyde, $\mathrm{BF}_{3} \cdot \mathrm{OEt}_{2}, 1,2$-dichloroethane, yield: $14 \%$; vii) $\mathrm{CuSO}_{4} \cdot 5 \mathrm{H}_{2} \mathrm{O}$, sodium ascorbate, $\mathrm{DMF}$, yield: $72 \%$. 

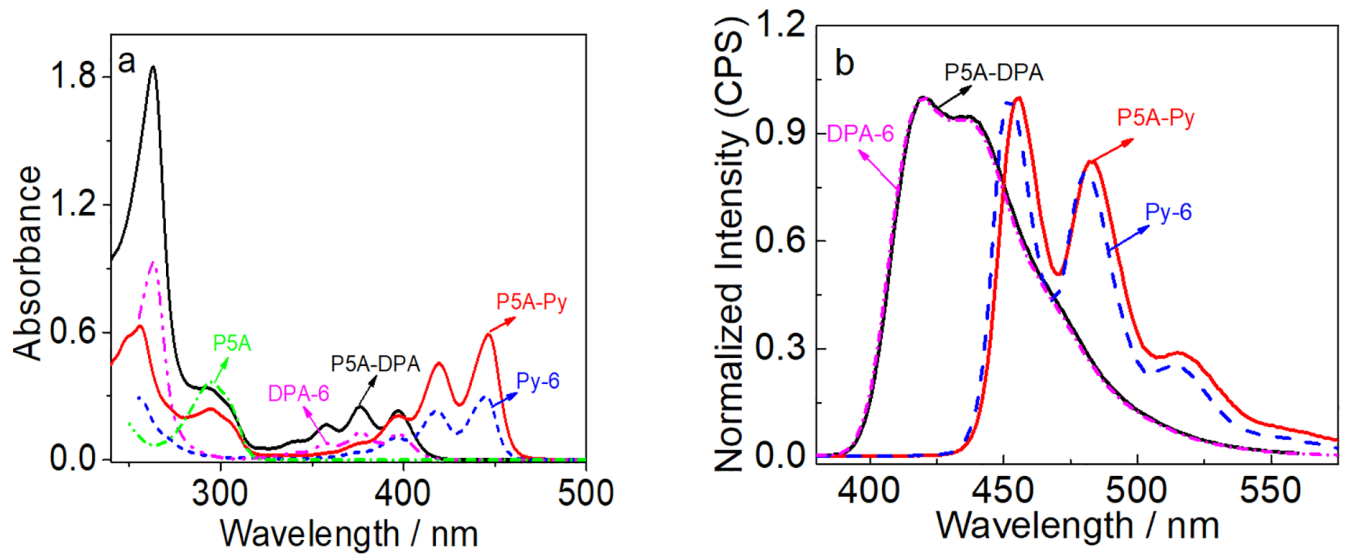

Figure 1: UV-vis absorption (a) and fluorescence emission spectra (b) of Py-6, P5A-Py $\left(\lambda_{\mathrm{ex}}=420 \mathrm{~nm}\right)$ and DPA-6, P5A-DPA $\left(\lambda_{\mathrm{ex}}=375 \mathrm{~nm}\right)$ in $\mathrm{CHCl}_{3}, \mathrm{c}=1.0 \times 10^{-5} \mathrm{M}, 25^{\circ} \mathrm{C}$.

almost the result of the addition of the spectra of pillar[5]arene with DPA-6 and Py-6. The molar extinction coefficient at the longer wavelength for P5A-DPA was almost double that of DPA-6, e.g., $\varepsilon=23100 \mathrm{M} \mathrm{cm}^{-1}$ for P5A-DPA vs $12200 \mathrm{M} \mathrm{cm}^{-1}$ for DPA-6 at $397 \mathrm{~nm}$, indicating that there is no strong interaction between the two DPA units in P5A-DPA at the ground state. Similar results were observed for P5A-Py except for a slight bathochromic shift of the absorption compared with Py-6.

The fluorescence spectrum of P5A-DPA is very similar to that of DPA-6 (Figure 1b). P5A-DPA showed an intense fluorescence in the visible light region, peaked at $420 \mathrm{~nm}$ with a shoulder at $437 \mathrm{~nm}$ and a fluorescence quantum yield as high as $89.5 \%$, which is very close to that of DPA-6 $\left(\Phi_{\mathrm{F}}=92.1 \%\right)$. For P5A-Py, however, it showed a slightly red-shifted emission compared with Py-6, with the emission peaks at $456 \mathrm{~nm}$ and $483 \mathrm{~nm}$ and a shoulder at $516 \mathrm{~nm}$ (Table 1). The quantum yield was significantly decreased to $46.4 \%$ compared with $78.2 \%$ for Py-6. We ascribed the decreased fluorescence of P5A-Py to the $\pi-\pi$ stacking of the Py units caused by the high local concentration of perylene. For P5A-DPA, which also bears two DPA units in one macrocyclic host, the fluorescent quantum yield was only slightly decreased. This should be mainly due to the steric hindrance of the 9- and 10-phenyl groups, which inhibited the $\pi-\pi$ stacking of the anthracene core in DPA.

The fluorescent lifetimes of P5A-Py and P5A-DPA were compared with Py-6 and DPA-6. As shown in Figure 2, the lifetime of P5A-Py is $3.4 \mathrm{~ns}$ which is shorter than that of Py-6 (4.4 ns), demonstrating that grafting two Py units in close proximity in one host, opened a new route for nonradiative decay. This phenomenon further verified the occurrence of $\pi-\pi$ stacking of the Py fragments in P5A-Py. The lifetime of P5A-DPA was $4.8 \mathrm{~ns}$, which is very similar to DPA-6 (5.0 ns) and the non-substituted DPA (5.3 ns) [42]. The fact that grafting DPA units in one host did not influence the fluorescent quantum yield together with the appealing host-guest properties make P5A-DPA an ideal candidate for applications as acceptor for triplet-triplet annihilation upconversion.

\section{Optical properties}

Due to the fact that the Py and DPA units are too large to enter the cavity of the pillar[5]arene, we expected that the oxygen-

Table 1: Photophysical parameters of the synthesized monomers Py-6, DPA-6 and the planar-chiral hosts P5A-Py, P5A-DPA. ${ }^{\text {a }}$

\begin{tabular}{|c|c|c|c|c|c|}
\hline & $\lambda_{\text {abs }} / \mathrm{nm}$ & $\varepsilon^{b}$ & $\lambda_{\mathrm{em}} / \mathrm{nm}$ & $\Phi_{\mathrm{F}}{ }^{\mathrm{C}}$ & $\tau_{\mathrm{F} / \mathrm{ns}}{ }^{\mathrm{d}}$ \\
\hline P5A-DPA & $295,376,397$ & $3.04,2.50,2.31$ & 420,437 & 89.5 & 4.75 \\
\hline DPA-6 & 376,397 & $1.30,1.22$ & 420,435 & 92.1 & 4.95 \\
\hline P5A-Py & $295,419,446$ & $2.39,4.53,5.88$ & $456,483,516$ & $46.4^{d}$ & 3.36 \\
\hline Py-6 & 418,445 & $2.31,2.99$ & $451,480,514$ & $78.2^{d}$ & 4.40 \\
\hline
\end{tabular}

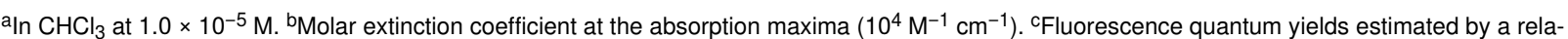
tive method using DPA ( $\Phi_{\mathrm{F}}=95 \%$ in ethanol) as the standard. ${ }^{\mathrm{d}}$ Perylene $\left(\Phi_{\mathrm{F}}=98 \%\right.$ in $n$-hexane) as the standard. ${ }^{\mathrm{d}}$ Fluorescence lifetimes. 

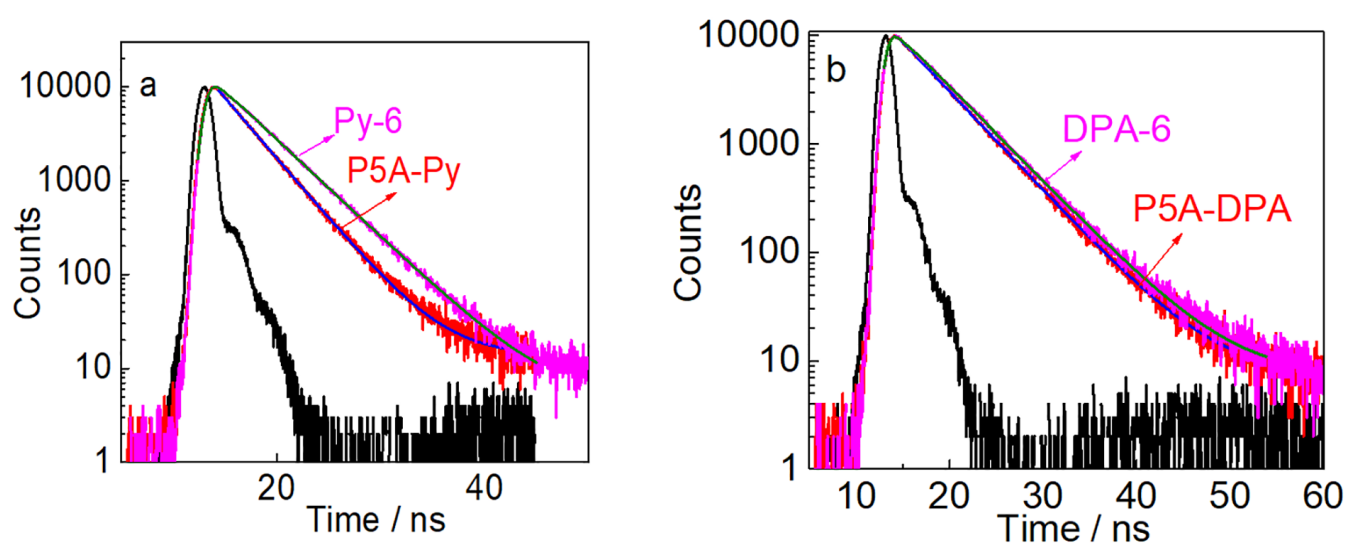

Figure 2: (a) Fluorescence decay curves of Py-6 and P5A-Py at $450 \mathrm{~nm}$ and (b) fluorescence decay curves of DPA-6 and P5A-DPA at $420 \mathrm{~nm}$, excited at $390 \mathrm{~nm}$ nanosecond LED, $c=1.0 \times 10^{-5} \mathrm{M}$ in $\mathrm{CHCl}_{3}, 25^{\circ} \mathrm{C}$.

through-annulus rotation is blocked in P5A-DPA and P5A-Py, giving rise to two pairs of enantiomeric pillar[5]arene derivatives. The racemic mixtures of P5A-DPA and P5A-Py were respectively separated by chiral high-performance liquid chromatography (HPLC). As shown in Figure 3a, injection of a P5ADPA solution onto a DAICEL CHIRALPAK IA chiral HPLC column afforded two well-separated peaks of almost equal areas at $8.8 \mathrm{~min}$ and $10.0 \mathrm{~min}$, respectively, demonstrating that P5ADPA was the racemic mixture of $R_{p}$ and $S_{p}$ configuration. The two fractions were collected separately and re-injected into the chiral column to confirm the enantiomeric purity and to check if racemization of the enantiomers takes place in solution at room temperature. In both cases, only the original peak was detected and the peak for the antipodal enantiomer was not detected, indicating that no racemization of the enantiomer of P5A-DPA takes place at room temperature (Figure $3 b$ and c). P5A-Py showed a similar phenomenon (Figure S22a,b and c). These results demonstrated that the bulky substituents DPA or perylene effectively prevent the ring rotations, and therefore making the separation of $R_{p}$ and $S_{p}$ conformers possible.
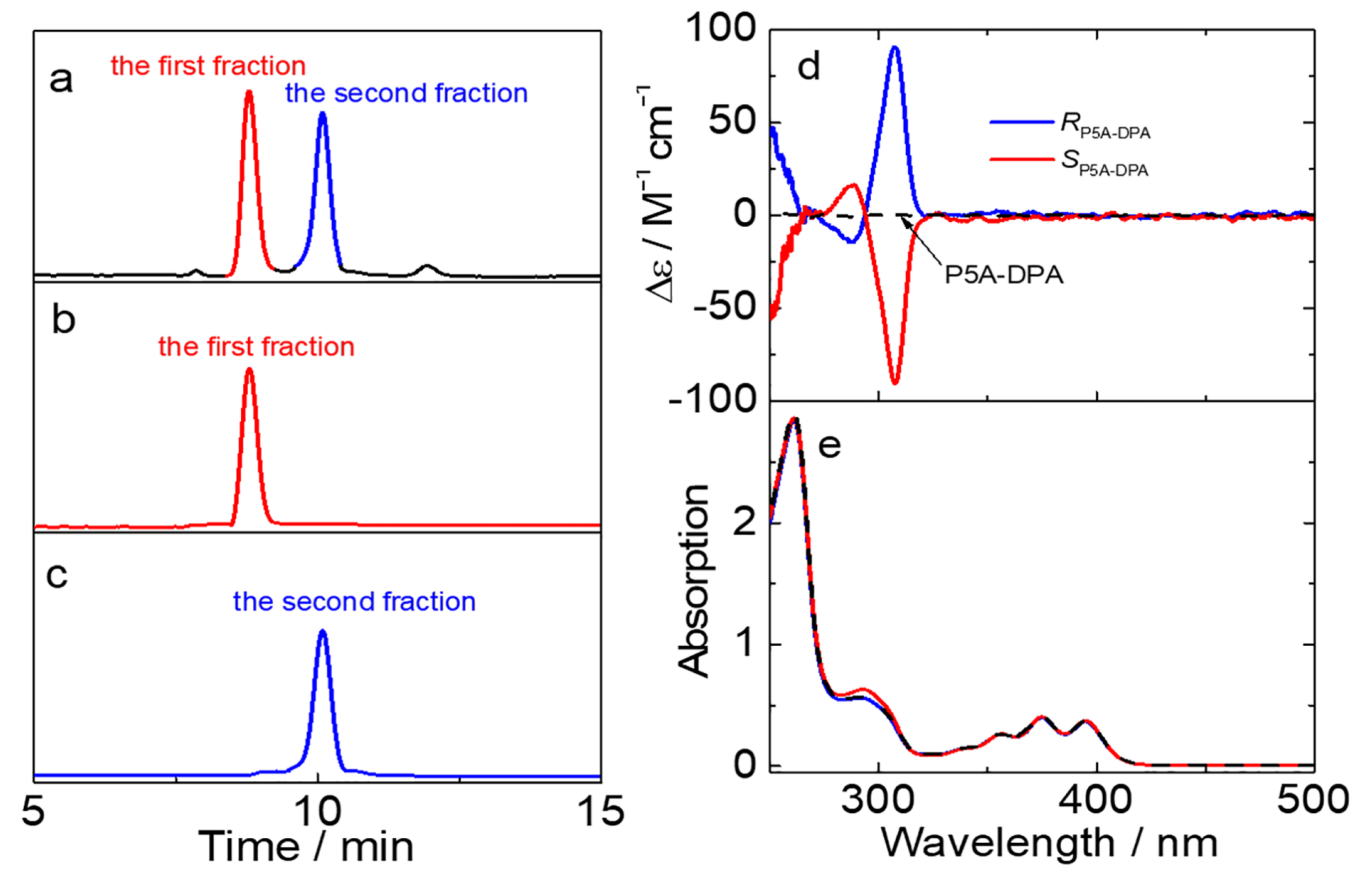

Figure 3: (a) Chiral HPLC traces of P5A-DPA, (b), (c) the first and second fractions of P5A-DPA, detected by UV at $295 \mathrm{~nm}$. Conditions: column, DAICEL CHIRALPAK IA; mobile phase: hexane/dichloromethane 35:65; flow rate $=4.0 \mathrm{~mL} / \mathrm{min}$; temperature $\left.25^{\circ} \mathrm{C}\right)$. (d) $\mathrm{CD}$ and $(\mathrm{e}) \mathrm{UV}-\mathrm{vis}$ spectra of racemic P5A-DPA, the first and second fractions $(10 \mu \mathrm{M})$ in $\mathrm{CHCl}_{3}$ at $25{ }^{\circ} \mathrm{C}$. 
Figure $3 \mathrm{~d}$ and e show the circular dichroism (CD) and UV-vis spectra of each fraction for P5A-DPA. The CD signals of both fractions observed at $270-320 \mathrm{~nm}$ are perfect mirror images, thus confirming that the two fractions contain a pair of enantiomers. The positive Cotton effect observed at ca. $310 \mathrm{~nm}$ was assigned to the $R_{p}$ configured enantiomer whereas the negative Cotton effect at ca. $310 \mathrm{~nm}$ was assigned to the corresponding $S_{p}$ configured isomer, based on calculations as well as singlecrystal X-ray diffraction published recently [20]. Thus, the absolute configuration of the first fraction was assigned to be $S_{p}$ and the second fraction was assigned to the $R_{p}$ isomer. Unexpectedly, no induced CD signals of DPA units at 360-420 nm were observed though P5A-DPA showed a strong absorption (with $\varepsilon>10^{4} \mathrm{M}^{-1} \mathrm{~cm}^{-1}$, Figure $3 \mathrm{e}$ ) in this region. The same is true for P5A-Py (Supporting Information File 1, Figure S22d and e). We attributed the absence of induced CD signals to the long distances of the fluorophores to the chiral center and therefore chirality transfer is non-effective [43].

Supramolecular assembly usually leads to different photophysical properties than homogeneous solutions. We have demonstrated that solvents play a critical role in chiral recognition and chiral photoreactions [44-51]. We therefore further investigated the solvent-induced aggregation behaviors of the chirally pure conformers by adding different proportions of water into their
THF solutions. Taking the $R_{p}$ conformers for example, the aggregation of P5A-DPA is apparently divided into two stages (Figure 4). By adding 50\% water to THF, the UV-vis absorption wavelength of P5A-DPA did not change but the CD signals were obviously enhanced. This is most probably due to the formation of aggregates and the rotation of the phenolic units in pillar[5]arene host was inhibited in the aggregates. The aggregation behavior was further investigated by dynamic light scattering (DLS) analyses, and revealed the formation of nanoparticles with $615 \mathrm{~nm}$ in average diameter after the addition of $50 \%$ water (Figure $4 \mathrm{~d}$ ). Increasing the amount of water to $70 \%$ or $90 \%$ led to a bathochromic shift of the UV-vis absorption and a raise of the baseline, indicating particles of larger size were formed. The CD signals continuously increased accompanied with a red-shifting of the wavelength, thus demonstrating that the DPA pigments started to aggregate in solutions with a water content of more than $50 \%$. The $\pi-\pi$ stacking of the anthracene core in DPA is responsible for the red-shift of the absorption. For P5A-Py, however, adding water to the THF solution led to a continuous red-shifting of the UV-vis spectra and increasing of CD signal, which is reasonable, as the planar structure of Py tends more to get aggregated in water by $\pi-\pi$ stacking. Aggregates with an average diameter of $531 \mathrm{~nm}$ are formed in $60 \%$ water (Figure S23, Supporting Information File 1) [52]. Exciton coupling CD (ECCD) signals were not ob-
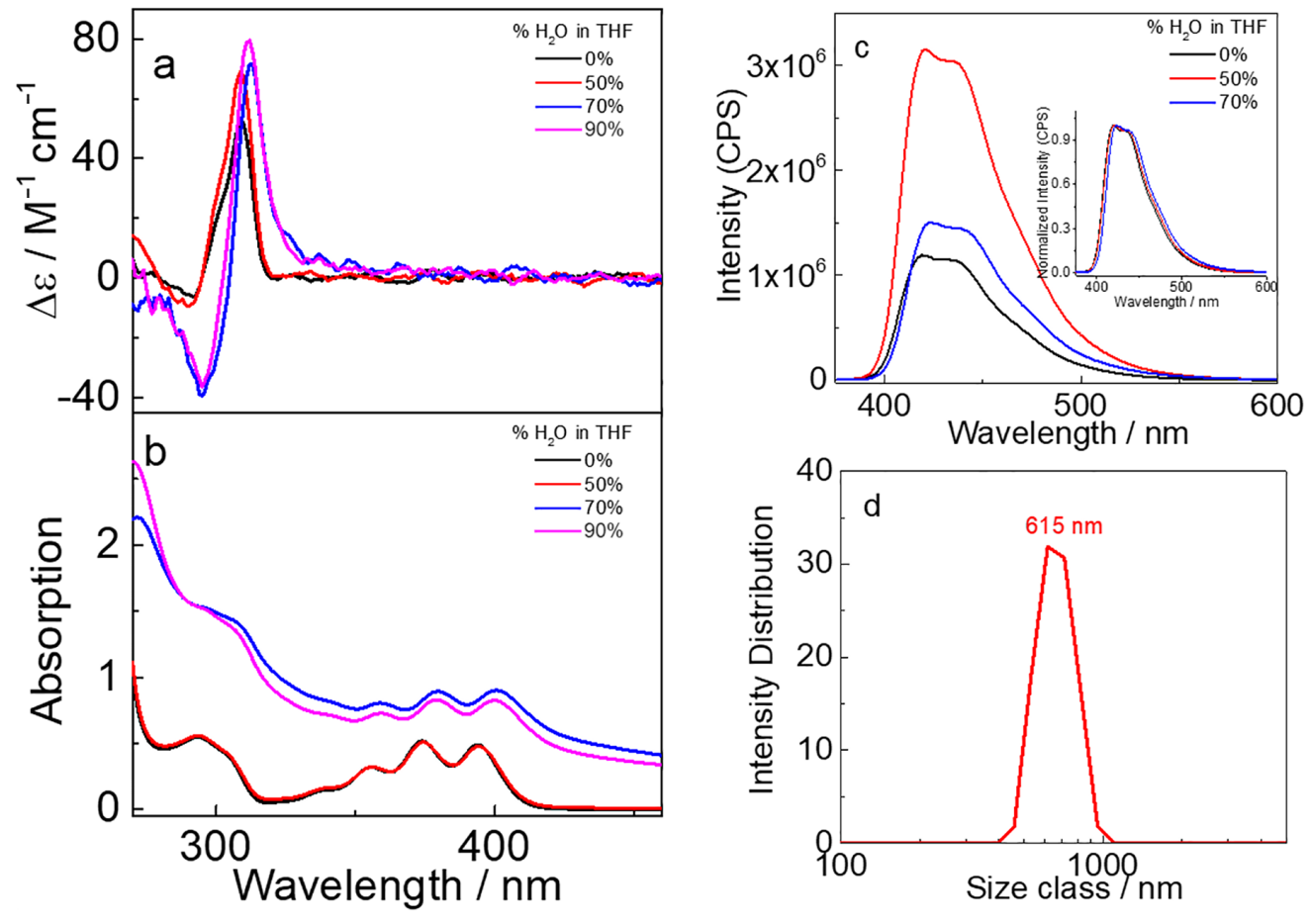

Figure 4: (a) CD, (b) UV-vis and (c) fluorescence spectra of the $R_{\text {P5A-DPA }}(20 \mu \mathrm{M})$ in THF and THF/ $\mathrm{H}_{2} \mathrm{O}$ solvent mixtures; inset: the normalized fluorescence spectrum. (d) DLS measurements of the aggregated $R_{\text {P5A-DPA }}$ obtained from the mixture of THF/ $\mathrm{H}_{2} \mathrm{O} 1: 1(\mathrm{v} / \mathrm{v})$. 
served for both compounds, even when adding more than $90 \%$ water, demonstrating that the chromophores DPA or Py units were not asymmetrically oriented in the aggregates.

Interestingly, by adding water into the THF solution of P5ADPA, the fluorescence intensity firstly increased by 3 times at $50 \%$ water and then decreased when the water content was increased to $70 \%$ (Figure $4 \mathrm{c}$ ). We attributed the enhanced emission of P5A-DPA in the presence of less than 50\% water to an inhibited rotation of the 9,10-phenyl groups in the DPA units, which reduced the inactivation of the excited state through nonradiative transition [53]. However, when increasing the amount of water, the fluorescence starts to decrease due to the $\pi-\pi$ stacking of DPA, which led to aggregation-caused quenching (ACQ), as was demonstrated by UV-vis absorption and CD studies. For compound P5A-Py, however, the fluorescence intensity continuously decreased when adding water into the THF solutions, and at $70 \%$ water content, a new emission peak at $540 \mathrm{~nm}$ was observed which was assigned to the excimer emission of Py (Figure S23, Supporting Information File 1) [54].

\section{Conclusion}

Two new planar chiral macrocyclic hosts P5A-DPA and P5APy were synthesized by grafting two fluorophore pigments (DPA or Py) on pillar[5]arene through CuAAC "click" reaction. The new macrocyclic compounds showed strong absorptions in the visible range and high fluorescence quantum yield, e.g., P5A-DPA showed absorption at 350-410 $\mathrm{nm}$ and a quantum yield of $89.5 \%$ which is comparable to the monomer DPA-6. On the other hand, P5A-Py with two perylene (Py) pigments grafted on the pillar[5] arene showed intense absorption at $385-460 \mathrm{~nm}$ and a quantum yield of $46.4 \%$. The rotation of phenolic units was inhibited by introducing two bulky fluorophores in one of the phenolic units of pillar[5]arene, and the enantiomers were isolated by chiral HPLC. The absolute configurations of each fraction were determined by circular dichroism (CD) spectroscopy. The first fraction showing negative CD signals was assigned to the $S_{p}$ conformer and the second fraction showing positive CD signals was assigned to the $R_{p}$ conformer. Aggregation behaviors of the enantiopure chiral pillar[5] arene derivatives were investigated by adding water into the THF solution. P5A-DPA and P5A-Py showed an enhancement of the $\mathrm{CD}$ signals by adding water due to restriction of the conformers' rotations by aggregation. P5A-DPA showed a fluorescence enhancement when less than $50 \%$ of water was added, while P5A-Py showed emission quenching and excimer emission when adding water into the THF solution. This work presented a new strategy for achieving versatile planar chiral hosts, and these hosts will have potential applications in various fields such as supramolecular sensing, host-guest recognition and triplet-triplet annihilation upconversion.

\section{Experimental}

\section{General materials and methods}

All reagents and chemicals used in synthesis were analytically pure and used as received without further purification. ${ }^{1} \mathrm{H}$ NMR and ${ }^{13} \mathrm{C}$ NMR spectra were recorded at room temperature on a Bruker AMX-400 spectrometer (operating at $400 \mathrm{MHz}$ for ${ }^{1} \mathrm{H}$ NMR and $100 \mathrm{MHz}$ for ${ }^{13} \mathrm{C} \mathrm{NMR}$ ) in $\mathrm{CDCl}_{3}$ with TMS as an internal standard. Due to the poor solubility, NMR spectra of P5A-DPA were recorded at room temperature on a Bruker AMX-600 spectrometer (operating at $600 \mathrm{MHz}$ for ${ }^{1} \mathrm{H}$ NMR and $151 \mathrm{MHz}{ }^{13} \mathrm{C} \mathrm{NMR}$ ) in $\mathrm{CDCl}_{3}$. High-resolution mass spectra (HRMS) were measured using a Waters-Q-TOF Premiers (ESI) apparatus. UV-vis spectra were obtained on a JASCO v-650 spectrometer. Fluorescence spectra and fluorescence lifetime decay measurements were recorded on a HORIBA FluoroMax-4 (TCSPC) spectrofluorimeter. Circular dichroism spectra were measured on a JASCO J-1500 spectrometer using a quartz cuvette of $1 \mathrm{~cm}$ path length installed in a Unisoku cryostat. Dynamic light scattering (DLS) studies were done on a Zetasizer Nano ZS90 instrument. A preparative Chiralpak IA column was used for the separation of enantiomers.

\section{Synthesis and characterization of P5A-DPA}

The synthesis and characterization data of P5A-Py have been reported elsewhere [34].

Synthesis of 2: In a similar manner as described previously [55]. An aqueous solution of $\mathrm{K}_{2} \mathrm{CO}_{3}(5.4 \mathrm{~g}, 39.0 \mathrm{mmol})$ and $\mathrm{CsF}$ (3.7 g, $24.3 \mathrm{mmol}$ ) was added to the solution of compound 1 (5.0 g, $19.5 \mathrm{mmol})$ and phenylboronic acid (3.6 g, $25.4 \mathrm{mmol})$ in the mixed solvent of toluene $(40 \mathrm{~mL})$, tetrahydrofuran $(60 \mathrm{~mL})$ and water $(10 \mathrm{~mL})$. After bubbling argon through the mixture for $15 \mathrm{~min}, \mathrm{Pd}\left(\mathrm{PPh}_{3}\right)_{4}(300 \mathrm{mg}, 0.3 \mathrm{mmol})$ was added, and the mixture was stirred and refluxed for $8 \mathrm{~h}$. Then, the reaction mixture was extracted with dichloromethane, and the organic layer was dried over anhydrous $\mathrm{Na}_{2} \mathrm{SO}_{4}$. The solution was concentrated under reduced pressure to obtain the crude product which was further purified by chromatography (silica gel, dichloromethane/petroleum ether 30:1) to afford compound 2 as white solid $(4.8 \mathrm{~g}, 82.0 \%)$. Mp $156{ }^{\circ} \mathrm{C}$; the ${ }^{1} \mathrm{H}$ NMR spectrum of $\mathbf{2}$ is shown in Figure S1, Supporting Information File 1. ${ }^{1} \mathrm{H}$ NMR (400 MHz, $\left.\mathrm{CDCl}_{3}\right) 8.49(\mathrm{~s}, 1 \mathrm{H}), 8.04(\mathrm{~d}, J=$ $8.5 \mathrm{~Hz}, 2 \mathrm{H}), 7.67(\mathrm{~d}, J=8.8 \mathrm{~Hz}, 2 \mathrm{H}), 7.60-7.51(\mathrm{~m}, 3 \mathrm{H})$, 7.47-7.42 (m, 4H), 7.36-7.34 (m, 2H). The ${ }^{13} \mathrm{C}$ NMR spectrum of 2 is shown in Figure S2, Supporting Information File 1. ${ }^{13} \mathrm{C}$ NMR (100 MHz, $\mathrm{CDCl}_{3}$ ) 138.76, 137.01, 130.33, 131.22, 130.18, 128.34, 128.30, 127.42, 126.81, 126.52, 125.30, 125.07. The electrospray ionization mass spectrum of $\mathbf{2}$ is shown in Figure S3, Supporting Information File 1. HRESIMS $(\mathrm{m} / \mathrm{z})$ : $[\mathrm{M}]^{+}$calcd for $\left[\mathrm{C}_{20} \mathrm{H}_{14}\right]^{+}, 254.1096$, found, 254.1125; $[\mathrm{M}+\mathrm{Na}]^{+}$calcd for $\left[\mathrm{C}_{20} \mathrm{H}_{14} \mathrm{Na}\right]^{+}, 277.0993$; found, 277.1268. 
Synthesis of 3: In a Schlenk tube under argon, compound 2 (2.5 g, $10.0 \mathrm{mmol})$ and $\mathrm{N}$-bromobutanimide $(2.1 \mathrm{~g}, 12.0 \mathrm{mmol})$ were dissolved in chloroform $(30.0 \mathrm{~mL})$. The mixture was heated at $60{ }^{\circ} \mathrm{C}$ for $2 \mathrm{~h}$ and then the solvent evaporated under reduced pressure. Afterwards, dichloromethane and water were added, and the organic layer was collected and dried over anhydrous $\mathrm{Na}_{2} \mathrm{SO}_{4}$. The crude product was purified by column chromatography using dichloromethane/petroleum ether 20:1 as the eluent to yield 3 as white solid $(2.8 \mathrm{~g}, 87 \%)$. Mp $154-155{ }^{\circ} \mathrm{C}$. The ${ }^{1} \mathrm{H}$ NMR spectrum of $\mathbf{3}$ is shown in Figure S4, Supporting Information File 1. ${ }^{1} \mathrm{H}$ NMR $\left(400 \mathrm{MHz}, \mathrm{CDCl}_{3}\right)$ $8.61(\mathrm{~d}, J=8.9 \mathrm{~Hz}, 2 \mathrm{H}), 7.64(\mathrm{~d}, J=8.7 \mathrm{~Hz}, 2 \mathrm{H}), 7.61-7.53(\mathrm{~m}$, $5 \mathrm{H}), 7.42-7.33(\mathrm{~m}, 4 \mathrm{H})$. The ${ }^{13} \mathrm{C}$ NMR spectrum of $\mathbf{3}$ is shown in Figure S5, Supporting Information File $1 .{ }^{13} \mathrm{C}$ NMR $\left(100 \mathrm{MHz}, \mathrm{CDCl}_{3}\right) 138.38,137.79,131.12,131.02,130.22$, $128.43,127.83,127.73,127.47,127.38,126.93,125.52,122.71$. The electrospray ionization mass spectrum of $\mathbf{3}$ is shown in Figure S6, Supporting Information File 1. HRESIMS $(\mathrm{m} / \mathrm{z})$ : $[\mathrm{M}]^{+}$calcd for $\left[\mathrm{C}_{20} \mathrm{H}_{13} \mathrm{Br}\right]^{+}$, 332.0201; found, 332.1679.

Synthesis of 4: Compound 4 was prepared by a similar procedure as that used for $\mathbf{2}$, but with $\mathbf{3}(1.5 \mathrm{~g}, 70 \%)$ as the starting material. The ${ }^{1} \mathrm{H}$ NMR spectrum of 4 is shown in Figure S7, Supporting Information File 1. Mp 245-247 ${ }^{\circ} \mathrm{C} ;{ }^{1} \mathrm{H}$ NMR $\left(400 \mathrm{MHz}, \mathrm{CDCl}_{3}\right)$ 7.77-7.72 (m, 2H), 7.71-7.65 (m, 2H), $7.63-7.57(\mathrm{~m}, 2 \mathrm{H}), 7.57-7.52(\mathrm{~m}, 1 \mathrm{H}), 7.48-7.46(\mathrm{~m}, 2 \mathrm{H})$, 7.37-7.30 (m, 6H), 7.09-7.04 (m, 2H). The ${ }^{13} \mathrm{C}$ NMR spectrum of $\mathbf{4}$ is shown in Figure S8, Supporting Information File 1. ${ }^{13} \mathrm{C} \mathrm{NMR}\left(100 \mathrm{MHz}, \mathrm{CDCl}_{3}\right)$ 154.97, 139.08, 136.98, 136.75, 132.57, 131.31, 130.18, 129.89, 129.66, 128.39, 127.44, 126.97, $126.94,124.97,124.94,120.78,115.35,115.27$. The electrospray ionization mass spectrum of $\mathbf{4}$ is shown in Figure S9, Supporting Information File 1. HRESIMS $(m / z)$ : $[\mathrm{M}-\mathrm{H}]^{-}$ calcd for $\left[\mathrm{C}_{26} \mathrm{H}_{17} \mathrm{O}\right]^{-}, 345.1279$; found, 345.1277.

Synthesis of 5: Under nitrogen atmosphere, a mixture of compound 4 (800.0 mg, $2.3 \mathrm{mmol}), \mathrm{K}_{2} \mathrm{CO}_{3}(952.2 \mathrm{mg}, 6.9 \mathrm{mmol})$ and 1,5-dibromopentane (1.1 g, $4.6 \mathrm{mmol})$ was dissolved in $30 \mathrm{~mL}$ dry acetone and the mixture was heated under reflux for $30 \mathrm{~h}$. After cooling, the solvents were removed under reduced pressure and the residue was purified by column chromatography on silica gel (100-200 mesh) using a mixture dichloromethane/petroleum ether 1:1 as the eluent to give compound 5 in $67 \%$ yield, $760.8 \mathrm{mg}$. Mp $155.6-161.1{ }^{\circ} \mathrm{C}$. The ${ }^{1} \mathrm{H}$ NMR spectrum of 5 is shown in Figure S10, Supporting Information File 1. ${ }^{1} \mathrm{H}$ NMR $\left(400 \mathrm{MHz}, \mathrm{CDCl}_{3}\right) 7.78-7.72(\mathrm{~m}, 2 \mathrm{H})$, 7.71-7.66 (m, 2H), $7.58(\mathrm{~d}, J=15.4 \mathrm{~Hz}, 3 \mathrm{H}), 7.49-7.45(\mathrm{~m}$, $2 \mathrm{H}), 7.34(\mathrm{~d}, J=13.6 \mathrm{~Hz}, 6 \mathrm{H}), 7.12(\mathrm{~d}, J=8.7 \mathrm{~Hz}, 2 \mathrm{H}), 4.12(\mathrm{t}$, $J=6.3 \mathrm{~Hz}, 2 \mathrm{H}), 3.50(\mathrm{t}, J=6.8 \mathrm{~Hz}, 2 \mathrm{H}), 2.02(\mathrm{~d}, J=14.7 \mathrm{~Hz}$, $2 \mathrm{H}), 1.96-1.88(\mathrm{~m}, 2 \mathrm{H}), 1.73(\mathrm{~d}, J=8.5 \mathrm{~Hz}, 2 \mathrm{H})$. The ${ }^{13} \mathrm{C}$ NMR spectrum of 5 is shown in Figure S11, Supporting
Information File 1. ${ }^{13} \mathrm{C}$ NMR (100 MHz, $\left.\mathrm{CDCl}_{3}\right)$ 158.46, 139.15, 136.97, 136.95, 132.41, 131.36, 131.07, 130.23, 129.93, 128.43, 127.47, 127.08, 126.98, 124.99, 124.93, 114.40, 67.70, $33.71,32.59,28.62,25.01$. The electrospray ionization mass spectrum of $\mathbf{4}$ is shown in Figure S12, Supporting Information File 1. HRESIMS $(\mathrm{m} / \mathrm{z}):[\mathrm{M}]^{+}$calcd for $\left[\mathrm{C}_{31} \mathrm{H}_{27} \mathrm{BrO}\right]^{+}$, 494.1245; found, 494.1265; $[\mathrm{M}+\mathrm{H}]^{+}$calcd for $\left[\mathrm{C}_{31} \mathrm{H}_{28} \mathrm{BrO}\right]^{+}$, 495.1324; found, 495.1264 .

Synthesis of DPA-6: To a solution of compound 5 (400.0 mg, $0.81 \mathrm{mmol})$ in DMF $(15 \mathrm{~mL})$ was added $\mathrm{NaN}_{3}(510.3 \mathrm{mg}$, $8.1 \mathrm{mmol}$ ). The mixture was stirred at $45^{\circ} \mathrm{C}$ for $4 \mathrm{~h}$ (monitored by TLC until complete consumption of the starting material). The reaction mixture was poured into water and the aqueous layer was extracted with ether $(3 \times 10 \mathrm{~mL})$. The combined organic layers were dried over $\mathrm{Na}_{2} \mathrm{SO}_{4}$ and concentrated in vacuo. The residue was purified by column chromatography on silica-gel (eluent: dichloromethane/petroleum ether 1:1) to give compound DPA-6 as pale yellow solid (310.8 mg, 84\%). Mp $140.2{ }^{\circ} \mathrm{C}$. The ${ }^{1} \mathrm{H}$ NMR spectrum of DPA-6 is shown in Figure S13, Supporting Information File 1. ${ }^{1} \mathrm{H}$ NMR $(400 \mathrm{MHz}$, $\left.\mathrm{CDCl}_{3}\right) 7.81-7.74(\mathrm{~m}, 2 \mathrm{H}), 7.72(\mathrm{~d}, J=7.4 \mathrm{~Hz}, 2 \mathrm{H}), 7.65-7.53$ $(\mathrm{m}, 3 \mathrm{H}), 7.53-7.46(\mathrm{~m}, 2 \mathrm{H}), 7.44-7.31(\mathrm{~m}, 6 \mathrm{H}), 7.17-7.11(\mathrm{~m}$, $2 \mathrm{H}), 4.14(\mathrm{t}, J=6.3 \mathrm{~Hz}, 2 \mathrm{H}), 3.39(\mathrm{t}, J=6.7 \mathrm{~Hz}, 2 \mathrm{H}), 2.00-1.89$ $(\mathrm{m}, 2 \mathrm{H}), 1.78(\mathrm{~d}, J=13.3 \mathrm{~Hz}, 2 \mathrm{H}), 1.72-1.63(\mathrm{~m}, 2 \mathrm{H})$. The ${ }^{13} \mathrm{C}$ NMR spectrum of DPA-6 is shown in Figure S14, Supporting Information File 1. ${ }^{13} \mathrm{C}$ NMR $\left(100 \mathrm{MHz}, \mathrm{CDCl}_{3}\right)$ 158.48, 139.16, 136.97, 132.43, 131.37, 131.07, 130.25, 129.95, 128.45, $127.48,127.10,127.05,125.01,124.95,114.40,67.69,51.46$, 29.01, 28.78, 23.57. The electrospray ionization mass spectrum of DPA-6 is shown in Figure S15, Supporting Information File 1. HRESIMS $(\mathrm{m} / \mathrm{z})$ : $[\mathrm{M}]^{+}$calcd for $\left.\left[\mathrm{C}_{31} \mathrm{H}_{27} \mathrm{~N}_{3} \mathrm{O}\right]^{+}\right)$, 457.2154; found, 457.2150; $[\mathrm{M}+\mathrm{H}]^{+}$calcd for $\left[\mathrm{C}_{31} \mathrm{H}_{28} \mathrm{~N}_{3} \mathrm{O}\right]^{+}$, 458.2232; found, 458.2213 .

Synthesis of P5A: Analogous as previously described [56]. To a solution of 1, 4-dimethoxybenzene $(1.7 \mathrm{~g}, 1.2 \mathrm{mmol})$ and 7 (55.8 mg, $0.3 \mathrm{mmol})$ in 1,2-dichloroethane $(150 \mathrm{~mL})$, paraformaldehyde $(271.5 \mathrm{mg}, 3.0 \mathrm{mmol})$ was added under nitrogen atmosphere. Then, boron trifluoride diethyl etherate $(120 \mu \mathrm{L})$ was added to the solution and the mixture was stirred at room temperature for $1 \mathrm{~h}$. Water $(100 \mathrm{~mL})$ was added to quench the reaction. The mixture was filtered and the solvent was removed. The residue was dissolved in dichloromethane. The organic layer was dried over anhydrous $\mathrm{Na}_{2} \mathrm{SO}_{4}$ and the solvent was evaporated to afford the crude product, which was isolated by flash column chromatography using ethyl acetate/petroleum ether 1:5 $(v / v)$ as the eluent to give P5A as white solid (108.8 mg, 14\%). The ${ }^{1} \mathrm{H}$ NMR spectrum of P5A is shown in Figure S16, Supporting Information File 1. ${ }^{1} \mathrm{H}$ NMR $(400 \mathrm{MHz}$, $\left.\mathrm{CDCl}_{3}\right) 6.82(\mathrm{~s}, 2 \mathrm{H}), 6.80(\mathrm{~s}, 2 \mathrm{H}), 6.79(\mathrm{~s}, 2 \mathrm{H}), 6.76(\mathrm{~s}, 2 \mathrm{H})$, 
$6.73(\mathrm{~s}, 2 \mathrm{H}), 4.49(\mathrm{~d}, J=2.3 \mathrm{~Hz}, 4 \mathrm{H}), 3.80-3.76(\mathrm{~m}, 10 \mathrm{H})$, 3.70-3.64 (m, 24H), $2.02(\mathrm{t}, J=2.3 \mathrm{~Hz}, 2 \mathrm{H})$. The ${ }^{13} \mathrm{C}$ NMR spectrum of P5A is shown in Figure S17, Supporting Information File $1 .{ }^{13} \mathrm{C}$ NMR $\left(100 \mathrm{MHz}, \mathrm{CDCl}_{3}\right) 150.71,150.67$, 150.64, 150.57, 149.33, 129.09, 128.37, 128.31, 128.03, 127.85, $115.74,114.23,113.96,113.86,113.71,78.87,74.72,56.36$, $55.83,55.79,55.64,29.69,29.61$. The electrospray ionization mass spectrum of P5A is shown in Figure S18, Supporting Information File 1. HRESIMS $(\mathrm{m} / \mathrm{z}):[\mathrm{M}+\mathrm{Na}]^{+}$calcd for $\left[\mathrm{C}_{49} \mathrm{H}_{50} \mathrm{NaO}_{10}\right]^{+}$, 821.3302; found, 821.3292.

Synthesis of P5A-DPA: A mixture of compound P5A (20.0 mg, $0.02 \mathrm{mmol})$, DPA-6 (47.2 mg, $0.1 \mathrm{mmol})$, $\mathrm{CuSO}_{4} \cdot 5 \mathrm{H}_{2} \mathrm{O}(12.0 \mathrm{mg}, 0.05 \mathrm{mmol})$, and sodium ascorbate $(19.0 \mathrm{mg}, 0.1 \mathrm{mmol})$ in DMF (5 mL) was refluxed under $\mathrm{N}_{2}$ atmosphere for 48 hours. The solvent was removed by rotary evaporation and the residue was purified by chromatography on silica gel (dichloromethane/ethyl acetate 30:1) to yield a brown solid (30.0 mg, 72\%). The ${ }^{1} \mathrm{H}$ NMR spectrum of P5A-DPA is shown in Figure S19, Supporting Information File 1. ${ }^{1} \mathrm{H}$ NMR $\left(600 \mathrm{MHz}, \mathrm{CDCl}_{3}\right) 7.71(\mathrm{~m}, J=10.6 \mathrm{~Hz}, 8 \mathrm{H}), 7.57(\mathrm{~m}, J=$ $7.2 \mathrm{~Hz}, 6 \mathrm{H}), 7.51-7.44(\mathrm{~m}, 4 \mathrm{H}), 7.34(\mathrm{~m}, J=9.9 \mathrm{~Hz}, 12 \mathrm{H})$, $7.22-6.75(\mathrm{~m}, 14 \mathrm{H}), 4.07-3.39(\mathrm{~m}, 40 \mathrm{H}), 2.97(\mathrm{~m}, 4 \mathrm{H})$, 2.14-1.59 (m, 14H). The ${ }^{13} \mathrm{C}$ NMR spectrum of P5A-DPA is shown in Figure S20, Supporting Information File $1 .{ }^{13} \mathrm{C}$ NMR (151 MHz, $\left.\mathrm{CDCl}_{3}\right)$ 171.17, 150.96, 139.08, 137.03, 136.89, $132.39,131.33,130.22,129.96,128.45,127.50,127.06,126.92$, $125.01,124.98,114.33,113.82,99.99,67.49,60.42,58.48$, $56.23,55.72,53.41,31.95,31.46,30.21,29.72,29.68,29.41$, $29.38,29.01,29.00,22.71,21.07,18.44,14.22$. The electrospray ionization mass spectrum of P5A-DPA is shown in Figure S21, Supporting Information File 1. HRESIMS $(\mathrm{m} / \mathrm{z})$ : $[\mathrm{M}+\mathrm{Na}]^{+}$calcd for $\left[\mathrm{C}_{111} \mathrm{H}_{104} \mathrm{~N}_{6} \mathrm{NaO}_{12}\right]^{+}, 1736.7643$; found, 1736.7744; $[\mathrm{M}+\mathrm{K}]^{+}$calcd for $\left[\mathrm{C}_{111} \mathrm{H}_{104} \mathrm{~N}_{6} \mathrm{KO}_{12}\right]^{+}$, 1753.1813; found, 1753.7510 .

\section{Supporting Information}

\section{Supporting Information File 1}

Characterization spectra of all compounds, chiral HPLC traces of P5A-Py, CD and UV-vis spectra of the two fractions P5A-Py and the aggregation behaviors of P5A-Py.

[https://www.beilstein-journals.org/bjoc/content/ supplementary/1860-5397-15-164-S1.pdf]

\section{Acknowledgements}

This work was supported by the National Natural Science Foundation of China (Nos. 21402129, 21871194, 21572142, 21372165 and 21321061), the National Key Research and De- velopment Program of China (No. 2017YFA0505903), and Science \& Technology Department of Sichuan Province (2019YJ0090, 2019YJ0160, 2017SZ0021). Comprehensive Training Platform of Specialized Laboratory, College of Chemistry and Prof. Peng Wu of Analytical \&Testing Center, Sichuan University for lifetime measurement are greatly appreciated.

\section{ORCID ${ }^{\circledR}$ iDs}

Guojuan Li - https://orcid.org/0000-0003-0910-2663 Chunying Fan - https://orcid.org/0000-0001-8884-6067 Wanhua Wu - https://orcid.org/0000-0002-8969-1148 Cheng Yang - https://orcid.org/0000-0002-2049-1324

\section{References}

1. Ôi, S.; Miyano, S. Chem. Lett. 1992, 21, 987-990. doi:10.1246/cl.1992.987

2. Hattori, T.; Harada, N.; Oi, S.; Abe, H.; Miyano, S. Tetrahedron: Asymmetry 1995, 6, 1043-1046. doi:10.1016/0957-4166(95)00120-e

3. Fiesel, R.; Huber, J.; Scherf, U. Angew. Chem., Int. Ed. Engl. 1996, 35, 2111-2113. doi:10.1002/anie.199621111

4. Fiesel, R.; Huber, J.; Apel, U.; Enkelmann, V.; Hentschke, R.; Scherf, U.; Cabrera, K. Macromol. Chem. Phys. 1997, 198, 2623-2650. doi:10.1002/macp.1997.021980901

5. Katoono, R.; Kawai, H.; Fujiwara, K.; Suzuki, T. Tetrahedron Lett. 2004, 45, 8455-8459. doi:10.1016/j.tetlet.2004.09.115

6. Wei, X.; Wu, W.; Matsushita, R.; Yan, Z.; Zhou, D.; Chruma, J. J.; Nishijima, M.; Fukuhara, G.; Mori, T.; Inoue, Y.; Yang, C. J. Am. Chem. Soc. 2018, 140, 3959-3974. doi:10.1021/jacs.7b12085

7. Rao, M.; Kanagaraj, K.; Fan, C.; Ji, J.; Xiao, C.; Wei, X.; Wu, W.; Yang, C. Org. Lett. 2018, 20, 1680-1683. doi:10.1021/acs.orglett.8b00520

8. Rao, M.; Wu, W.; Yang, C. Molecules 2019, 24, No. 1502. doi:10.3390/molecules24081502

9. Ogoshi, T.; Yamafuji, D.; Kotera, D.; Aoki, T.; Fujinami, S.; Yamagishi, T.-a. J. Org. Chem. 2012, 77, 11146-11152. doi:10.1021/jo302283n

10. Ogoshi, T.; Kanai, S.; Fujinami, S.; Yamagishi, T.-a.; Nakamoto, Y. J. Am. Chem. Soc. 2008, 130, 5022-5023. doi:10.1021/ja711260m

11. Si, W.; Chen, L.; Hu, X.-B.; Tang, G.; Chen, Z.; Hou, J.-L.; Li, Z.-T. Angew. Chem., Int. Ed. 2011, 50, 12564-12568. doi:10.1002/anie.201106857

12. Hu, X.-B.; Chen, Z.; Tang, G.; Hou, J.-L.; Li, Z.-T. J. Am. Chem. Soc. 2012, 134, 8384-8387. doi:10.1021/ja302292c

13. Li, H.; Chen, D.-X.; Sun, Y.-L.; Zheng, Y. B.; Tan, L.-L.; Weiss, P. S.; Yang, Y.-W. J. Am. Chem. Soc. 2013, 135, 1570-1576. doi:10.1021/ja3115168

14. Wei, P.; Li, D.; Shi, B.; Wang, Q.; Huang, F. Chem. Commun. 2015, 51, 15169-15172. doi:10.1039/c5cc06682d

15. Jie, K.; Zhou, Y.; Li, E.; Huang, F. Acc. Chem. Res. 2018, 51 , 2064-2072. doi:10.1021/acs.accounts.8b00255

16. Jie, K.; Zhou, Y.; Li, E.; Zhao, R.; Huang, F. Angew. Chem., Int. Ed. 2018, 57, 12845-12849. doi:10.1002/anie.201808998

17. Li, E.; Zhou, Y.; Zhao, R.; Jie, K.; Huang, F. Angew. Chem., Int. Ed. 2019, 58, 3981-3985. doi:10.1002/anie.201900140 
18. Ogoshi, T.; Kitajima, K.; Aoki, T.; Yamagishi, T.-a.; Nakamoto, Y. J. Phys. Chem. Lett. 2010, 1, 817-821. doi:10.1021/jz900437r

19. Gui, J.-C.; Yan, Z.-Q.; Peng, Y.; Yi, J.-G.; Zhou, D.-Y.; Su, D.; Zhong, Z.-H.; Gao, G.-W.; Wu, W.-H.; Yang, C. Chin. Chem. Lett. 2016, 27, 1017-1021. doi:10.1016/j.cclet.2016.04.021

20. Yao, J.; Wu, W.; Liang, W.; Feng, Y.; Zhou, D.; Chruma, J. J.; Fukuhara, G.; Mori, T.; Inoue, Y.; Yang, C. Angew. Chem., Int. Ed. 2017, 56, 6869-6873. doi:10.1002/anie.201702542

21. Lv, Y.; Xiao, C.; Yang, C. New J. Chem. 2018, 42, 19357-19359. doi:10.1039/c8nj04802a

22. Ogoshi, T.; Yamafuji, D.; Aoki, T.; Kitajima, K.; Yamagishi, T.-a.; Hayashi, Y.; Kawauchi, S. Chem. - Eur. J. 2012, 18, 7493-7500. doi:10.1002/chem.201200122

23. Kitajima, K.; Ogoshi, T.; Yamagishi, T.-a. Chem. Commun. 2014, 50, 2925-2927. doi:10.1039/c3cc49794a

24. Ogoshi, T.; Kitajima, K.; Aoki, T.; Fujinami, S.; Yamagishi, T.-a.; Nakamoto, Y. J. Org. Chem. 2010, 75, 3268-3273. doi:10.1021/jo100273n

25. Ogoshi, T.; Masaki, K.; Shiga, R.; Kitajima, K.; Yamagishi, T.-a. Org. Lett. 2011, 13, 1264-1266. doi:10.1021/ol200062j

26. Nierengarten, I.; Buffet, K.; Holler, M.; Vincent, S. P.; Nierengarten, J.-F. Tetrahedron Lett. 2013, 54, 2398-2402. doi:10.1016/j.tetlet.2013.02.100

27. Ogoshi, T.; Yamafuji, D.; Akutsu, T.; Naito, M.; Yamagishi, T.-a. Chem. Commun. 2013, 49, 8782-8784. doi:10.1039/c3cc44672g

28. Strutt, N. L.; Schneebeli, S. T.; Stoddart, J. F. Supramol. Chem. 2013, 25, 596-608. doi:10.1080/10610278.2013.822973

29. Strutt, N. L.; Fairen-Jimenez, D.; lehl, J.; Lalonde, M. B.; Snurr, R. Q.; Farha, O. K.; Hupp, J. T.; Stoddart, J. F. J. Am. Chem. Soc. 2012, 134, 17436-17439. doi:10.1021/ja3082523

30. Mastai, Y. Chem. Soc. Rev. 2009, 38, 772-780. doi:10.1039/b812587m

31. Wu, X.; Gao, L.; Hu, X.-Y.; Wang, L. Chem. Rec. 2016, 16, 1216-1227. doi:10.1002/tcr.201500265

32. Feng, W.; Jin, M.; Yang, K.; Pei, Y.; Pei, Z. Chem. Commun. 2018, 54, 13626-13640. doi:10.1039/c8cc08252a

33. Hu, X.-Y.; Gao, L.; Mosel, S.; Ehlers, M.; Zellermann, E.; Jiang, H.; Knauer, S. K.; Wang, L.; Schmuck, C. Small 2018, 14, No. 1803952. doi:10.1002/smll.201803952

34. Fan, C.; Wu, W.; Chruma, J. J.; Zhao, J.; Yang, C. J. Am. Chem. Soc. 2016, 138, 15405-15412. doi:10.1021/jacs.6b07946

35. Xu, W.; Liang, W.; Wu, W.; Fan, C.; Rao, M.; Su, D.; Zhong, Z.; Yang, C. Chem. - Eur. J. 2018, 24, 16677-16685 doi:10.1002/chem.201804001

36. Ogawa, T.; Yanai, N.; Monguzzi, A.; Kimizuka, N. Sci. Rep. 2015, 5, No. 10882. doi:10.1038/srep10882

37.Peng, H.-Q.; Chen, Y.-Z.; Zhao, Y.; Yang, Q.-Z.; Wu, L.-Z.; Tung, C.-H.; Zhang, L.-P.; Tong, Q.-X. Angew. Chem., Int. Ed. 2012, 51, 2088-2092. doi:10.1002/anie.201107723

38. Yu, G.; Zhang, Z.; Han, C.; Xue, M.; Zhou, Q.; Huang, F. Chem. Commun. 2012, 48, 2958-2960. doi:10.1039/c2cc00125j

39. Nierengarten, I.; Guerra, S.; Holler, M.; Nierengarten, J. F.; Deschenaux, R. Chem. Commun. 2012, 48, 8072-8074. doi:10.1039/c2cc33746k

40. Cao, D.; Kou, Y.; Liang, J.; Chen, Z.; Wang, L.; Meier, H. Angew. Chem., Int. Ed. 2009, 48, 9721-9723. doi:10.1002/anie.200904765

41. Liu, L.; Cao, D.; Jin, Y.; Tao, H.; Kou, Y.; Meier, H. Org. Biomol. Chem. 2011, 9, 7007-7010. doi:10.1039/c1ob05871a
42. Xu, K.; Zhao, J.; Escudero, D.; Mahmood, Z.; Jacquemin, D. J. Phys. Chem. C 2015, 119, 23801-23812. doi:10.1021/acs.jpcc.5b05325

43. Ogoshi, T.; Yamafuji, D.; Yamagishi, T.-a.; Brouwer, A. M. Chem. Commun. 2013, 49, 5468-5470. doi:10.1039/c3cc42612b

44. Yan, Z.; Huang, Q.; Liang, W.; Yu, X.; Zhou, D.; Wu, W.; Chruma, J. J.; Yang, C. Org. Lett. 2017, 19, 898-901. doi:10.1021/acs.orglett.7b00057

45. Dai, L.; Wu, W.; Liang, W.; Chen, W.; Yu, X.; Ji, J.; Xiao, C.; Yang, C. Chem. Commun. 2018, 54, 2643-2646. doi:10.1039/c8cc00840j

46. Yi, J.; Liang, W.; Wei, X.; Yao, J.; Yan, Z.; Su, D.; Zhong, Z.; Gao, G.; Wu, W.; Yang, C. Chin. Chem. Lett. 2018, 29, 87-90. doi:10.1016/j.cclet.2017.05.004

47. Alagesan, M.; Kanagaraj, K.; Wan, S.; Sun, H.; Su, D.; Zhong, Z.; Zhou, D.; Wu, W.; Gao, G.; Zhang, H.; Yang, C. J. Photochem. Photobiol., A 2016, 331, 95-101. doi:10.1016/j.jphotochem.2015.10.023

48. Wei, X.; Yu, X.; Zhang, Y.; Liang, W.; Ji, J.; Yao, J.; Rao, M.; Wu, W.; Yang, C. J. Photochem. Photobiol., A 2019, 371, 374-381. doi:10.1016/j.jphotochem.2018.11.038

49. Yang, C.; Wang, Q.; Yamauchi, M.; Yao, J.; Zhou, D.; Nishijima, M.; Fukuhara, G.; Mori, T.; Liu, Y.; Inoue, Y. Photochem. Photobiol. Sci. 2014, 13, 190-198. doi:10.1039/c3pp50255d

50. Yao, J.; Yan, Z.; Ji, J.; Wu, W.; Yang, C.; Nishijima, M.; Fukuhara, G.; Mori, T.; Inoue, Y. J. Am. Chem. Soc. 2014, 136, 6916-6919. doi:10.1021/ja5032908

51. Yang, C.; Inoue, Y. Chem. Soc. Rev. 2014, 43, 4123-4143. doi:10.1039/c3cs60339c

52. Wu, J.; Liang, W.; Niu, T.; Wu, W.; Zhou, D.; Fan, C.; Ji, J.; Gao, G.; Men, J.; Yang, Y.; Yang, C. Chem. Commun. 2018, 54, 9206-9209. doi:10.1039/c8cc03660h

53. Leung, N. L. C.; Xie, N.; Yuan, W.; Liu, Y.; Wu, Q.; Peng, Q.; Miao, Q.; Lam, J. W. Y.; Tang, B. Z. Chem. - Eur. J. 2014, 20, 15349-15353. doi:10.1002/chem.201403811

54. Basu, B. J.; Thirumurugan, A.; Dinesh, A. R.; Anandan, C.; Rajam, K. S. Sens. Actuators, B 2005, 104, 15-22. doi:10.1016/j.snb.2004.04.092

55. Zhong, F.; Zhao, J. Dyes Pigm. 2017, 136, 909-918. doi:10.1016/j.dyepig.2016.09.057

56. Wu, X.; Zhang, Y.; Lu, Y.; Pang, S.; Yang, K.; Tian, Z.; Pei, Y.; Qu, Y.; Wang, F.; Pei, Z. J. Mater. Chem. B 2017, 5, 3483-3487. doi:10.1039/c7tb00752c 


\section{License and Terms}

This is an Open Access article under the terms of the Creative Commons Attribution License

(http://creativecommons.org/licenses/by/4.0). Please note that the reuse, redistribution and reproduction in particular requires that the authors and source are credited.

The license is subject to the Beilstein Journal of Organic Chemistry terms and conditions:

(https://www.beilstein-journals.org/bjoc)

The definitive version of this article is the electronic one which can be found at:

doi:10.3762/bjoc.15.164 